\title{
Rigorous Experiments on Monkey Love: An Account of Harry F. Harlow's Role in the History of Attachment Theory
}

\author{
Stephen J. Suomi • Frank C. P. van der Horst • \\ René van der Veer
}

Published online: 8 August 2008

(C) The Author(s) 2008

\begin{abstract}
On the basis of personal reminiscences an account is given of Harlow's role in the development of attachment theory and key notions of attachment theory are being discussed. Among other things, it is related how Harlow arrived at his famous research with rhesus monkeys and how this made Harlow a highly relevant figure for attachment theorist Bowlby.
\end{abstract}

Keywords Attachment theory - Affectional systems · Ethology - Animal research · Harlow $\cdot$ Hinde $\cdot$ Spitz $\cdot$ Suomi $\cdot$ History of psychology $\cdot$ Biography

\section{Suomi's Background and Relationship with Harlow}

I grew up in Madison, Wisconsin, where Harry Harlow became famous for his research on surrogate monkey mothers (Harlow 1958), attracting widespread international public attention when I was in primary school. After secondary school I became an undergraduate at Stanford University, where I began studying psychology. I was initially a pre-medical student, but I took my first psychology course and my first organic chemistry course during the same academic term, and I

\footnotetext{
This paper is based on the verbatim record of an interview with Dr. Suomi conducted on September 27, 2006 at the Centre for Child and Family Studies, Leiden University by the second and third authors, who subsequently edited and annotated the text.
}

\section{S. J. Suomi}

Laboratory of Comparative Ethology, National Institute of Child Health \& Human Development, National Institutes of Health, DHHS, Bethesda, MD, USA

F. C. P. van der Horst $(\bowtie) \cdot$ R. van der Veer

Centre for Child and Family Studies, Leiden University, P.O. Box 9555,

2300RB Leiden, The Netherlands

e-mail: fhorst@fsw.leidenuniv.nl 
did very well in the former and not so well in the latter. I decided at that point I was really interested in psychology. It turned out that the very first question on the very first exam in my Introductory Psychology course was about Harlow's isolation studies, and I answered it well because by then I already knew Harlow's work by heart. As my undergraduate studies progressed I was accepted into an honours program in psychology and began doing research in social psychology, and I just absolutely fell in love with it. This probably kept me in school, because I also was getting interested in other things at the time.

For holidays I would usually go back to my parents' house in Madison. My father [Verner E. Suomi] was a long-time faculty member at the University of Wisconsin. He was also a noted scientist in his own right, a very prominent researcher in the field of meteorology who, among other things, had basically created the weather satellite system that we now have today. Prior to the spring break during my junior year at Stanford, he and Harlow ended up on the same airplane and found themselves sitting next to each other-at the time they were mutual acquaintances but not close friends. Sometime during the flight my father told Harlow that he had a son studying psychology at Stanford, which is where Harlow had gone to school himself, and he asked him if there was any information or advice Harlow might want to pass on to his son. So when I returned home for my spring break, there was a message waiting for me saying Harry Harlow wanted to see me. Well, I certainly knew who Harlow was, and I certainly made that appointment!

When I arrived at Harlow's office, he immediately sat me down and asked me what I had been doing at Stanford and what my plans were. I told him that I was very interested in social psychology and had started carrying out research in that area-and that I really wanted to go on to graduate school in that field. But what I did not tell him was that I had already checked out Wisconsin as a potential place to go to graduate school and had rejected the idea for two reasons in particular. One was I did not like the winters in Madison - and since I had discovered by that time that it was not necessary to nearly freeze to death every winter, my desire to return to the American midwest was about zero. Secondly, I had already checked out the social psychologists in the Wisconsin psychology department and although most were very prominent, they were studying things I was not particularly interested in at the time. So I replied to Harlow: "Yes, I am seriously looking at going to graduate school in the field of social psychology." He reacted by saying: "Well, that is interesting. But if you do that then you will end up with a pretty narrow background. Why don't you come and work with me instead?" That is how I got into the monkey business, because at the time I was not about to turn down his offer!

When I went back to Stanford for my spring term I had one elective opening in my class schedule, and it ultimately came down to a choice between two courses. One possibility was to take a course in physiological psychology from Charles Hamilton, who at that time was carrying out cortical lesion studies with monkeys. I knew that Harlow had conducted some pioneering research involving cortical lesions in monkeys, so it seemed like that course might be relevant for me. The other possibility was to take an advanced seminar from the noted developmental psychologist Eleanor Maccoby. I had never taken a developmental psychology course before, but the title of her seminar-Attachment and Dependency-sounded intriguing to me. Many years later Maccoby told me that she had somehow obtained 
a proof copy of John Bowlby's first book on attachment (Bowlby 1969/1982), and that is what she essentially based the seminar upon. So it turned out that my initial exposure to Bowlby and attachment theory occurred even before his first volume had been published - and before I started working with Harlow.

When I returned to Wisconsin to begin graduate school the following year [in February, 1968] I initially found Harlow to be very different from the person with whom I had met the previous spring. I subsequently learned that he had just found out that his wife Margaret had terminal cancer and that he had taken the news very badly - he had become clinically depressed. At any rate, I had only been in the lab for maybe two or three weeks when Harlow suddenly pulled me into his office one afternoon and told me: "Go find somewhere else to study. I am about to go to the Mayo Clinic for extended treatment. I do not know how long I am going to be away from here, and you might want to re-consider some of those other places you have applied to." I very quickly made my decision: No, I do not want to do that, I will stay around and see what happens. In the meantime a brilliant, active, enthusiastic, and newly tenured Associate Professor named Jim [Gene P.] Sackett, took me under his wings and in the ensuing 3-4 months taught me just about everything I know about experimental design and the observation of behavior. Sackett easily convinced me to do some research with him, and after we finished that experiment I conducted a follow-up study using the same apparatus. I wrote up the results, and when Harlow finally came back to the lab and read the manuscript, he told me: "Congratulations, you have just done your Master's thesis. Now let's go study something serious." That paper was my first scientific publication, with both Harlow and Sackett as co-authors (Suomi et al. 1970).

When I subsequently met with Harlow to discuss possible topics for my dissertation research, he told me: "There are two topics I am especially interested in these days. One involves the study of cognitive development, using tests like cross-string tasks to assess some advanced cognitive capabilities in young monkeys," but at the time I was not really interested in that. "The second involves developing a monkey model of depression."

After Harlow had been treated for his depression, he decided that he wanted to try to model it in monkeys, and he spent some time consulting with his good friend Bill [William] Lewis, who at that time was Chair of the Department of Psychiatry at Wisconsin, regarding the plausibility of developing a monkey model. Lewis was enthusiastic about that prospect, and Harlow proposed that I start the ball rolling by surveying what previous efforts to model human psychopathology in monkeys had yielded. He added that "There are some things in the literature that might help." It turned out that Harlow and his students had carried out some monkey experiments involving maternal separation in the previous decade, basing their studies on reports of the depressive consequences of maternal separation for human infants. He told me: "There are two people that you need to read: one of them is René Spitz and the other is John Bowlby, whom I know personally." So first of all he gave me all of his copies of Bowlby's reprints, which were not only autographed by Bowlby, but more interestingly, Harlow had written notes in the margins of the reprints. He later talked to me extensively about his relationship with Bowlby. So I knew about Bowlby and attachment theory before I met Harlow, but more importantly Harlow was the one who encouraged me to read Bowlby thoroughly and who started telling me about his work. 


\section{Harlow and Bowlby}

Harlow was introduced to Bowlby by the British ethologist Robert Hinde, who of course knew Bowlby well. What is interesting is that at the time that Bowlby was starting to develop his theory of attachment, Hinde was shifting his area of interest from studies of song-learning in birds to studies of mother-infant interactions in rhesus monkeys. The suggestion is that one of the reasons Hinde changed his area of interest was because he had visited Harlow some years earlier. So Harlow influenced Hinde, who then got Bowlby's attention, and then Hinde introduced Harlow to Bowlby - and they hit it off right away. They subsequently corresponded extensively, and Bowlby invited Harlow to several conferences at the CIBA-foundation that Bowlby, Hinde, and Harlow all attended (Foss 1961, 1963, 1965, 1969).

I think the best indication of the importance of these CIBA-conferences for Harlow's work is that Harlow insisted that Bowlby invite some of his best students and postdocs to the second and subsequent conferences. Harlow wanted his students to absorb both what was happening at the human level and where these people were coming from in terms of not only the empirical work they were carrying out but also the theoretical foundation upon which they were basing their studies. I am sure that Harlow had recognised long before his interactions with Bowlby that one could use monkeys to study behavioral phenomena that would be relevant for human development but that could not be done with rats and was not feasible, for ethical and/or practical reasons, to carry out with human subjects.

You could not carry out those studies with rats because rats do not have the all the advanced cognitive capabilities that the primate cortex makes possible. If all you are studying is conditioning, you do not need an organism with a well-developed cortex. However, if you limit yourself to studying conditioning processes, you are basically ignoring all the advanced cognitive capabilities that emerge during development that the primate brain provides. So Harlow thought that he could study aspects of human cognitive development and social behavior using monkeys where it was possible to rigorously control environments and vary the conditions and the stimulus presentation - and he could test those monkeys every day. It is all but impossible to do that with human subjects, especially children, because most parents and teachers are appropriately unwilling to have an experimenter show up in their house or their classroom every day. So Harlow realized that it is possible to collect much more complete information on individual monkeys than is typically the case with human subjects.

Bowlby visited Harlow's lab at least once, and that is how their relationship became well-established. If you look at Bowlby's (1958) first monograph on attachment, you will find in one of the footnotes a reference to Harlow's not yet published surrogate mother studies. Harlow was about to present his initial findings from that research publicly for the first time in his presidential address to the American Psychological Association in the summer of 1958. That address, which Harlow entitled "The nature of love," turned out to be an absolutely remarkable presentation, which became famous (at least among psychologists) not only for its scientific content but also for its style of presentation-I have numerous older colleagues who were in the audience when Harlow delivered that address who still remember the occasion. At any rate, Harlow apparently sent a copy of a draft of the talk to Bowlby before he published it in the American Psychologist (Harlow 1958). 
Bowlby included a reference to that paper as a footnote in his original 1958 monograph on attachment. Of course when Harlow gave me his copy of that paper, he had circled the footnote and said: "Pay attention to this!" So right from the beginning of attachment theory there was a biological component, and it was heavily influenced not only by Bowlby's previous interest in ethology, but also by his concurrent interest in the mother-infant studies that Harlow was modelling with his surrogate research and that Hinde was beginning to study in more naturalistic circumstances.

A few years later, shortly after I got my degree, Harlow introduced me to Bowlby at a meeting in New York. At that meeting, which involved a relatively small number of very prominent ethologists, psychiatrists, and comparative and developmental psychologists (including Bowlby, Hinde, and Mary Ainsworth, among others) Harlow insisted that I present the latest findings from the lab, saying "Steve, you are going to give this talk, not me." The conference began with that presentation (Suomi 1976), and Bowlby gave the talk that followed (Bowlby 1976) - and that is where we got to know one another. Shortly thereafter, Bowlby invited me to come to England and visit him at the Tavistock. That is how my own relationship with Bowlby got started-but Harlow's interactions with Bowlby predated that conference by almost two decades. Indeed, from the very beginning of his research with surrogates, Harlow was acutely aware of Bowlby and appreciated the importance of what he was trying to do with his ideas about attachment.

Regarding their personal relationship, I would say that they respected one another enormously. Harlow was a rebel in his own field who delighted in destroying theories as much as he could, and his initial experiment with surrogate monkey mothers all but demolished two of the most prominent contemporary theories at the same time. First of all, it knocked the socks off of the classic psychoanalytic view of how infants establish their initial relationships with caregivers, namely through oral gratification associated with nursing. It also clearly contradicted the prevailing psychological theory of primary and secondary drive reduction, which had at its heart the idea that an infant's desire to be with its caregivers stems from the reduction of the primary drive of hunger through feeding, i.e., this desire for the caregiver represents a secondary drive. Thus, both the prevailing psychoanalytic and behavioral views at the time held that relationships between parents and infants developed initially as a consequence of nursing. And Harlow's surrogate research, in which he demonstrated convincingly that rhesus monkey infants overwhelmingly preferred to be with cloth-covered surrogates that provided no source of milk to wire-covered surrogates that provided them with all the milk they could ever drink, showed that neither of those views could be correct. Bowlby of course spent much of his entire career fighting the classic orthodox psychoanalytic view. So I think they both saw that rebellious spirit in one another and had plenty to talk about regarding theories and data. And they also listened to each other's advice.

As one example of this, Harlow told me about a visit Bowlby once made to his lab after Harlow had finished his initial surrogate studies and was next trying to design a surrogate that would physically reject an infant, presumably to block the infant's development of an attachment to the surrogate. At the time of Bowlby's visit Harlow had already pilot-tested a variety of different models of "rejecting" surrogates. One model shook the infant off, another had a little catapult that would 
throw the infant off, a third surrogate that had little spikes that would come out of its body to discourage physical contact by the infant - and none of them worked. That is, every time the infant was physically rejected by each surrogate mother, as soon as the surrogate went back to its "normal" condition, the infant would immediately return to the surrogate. Harlow discussed with Bowlby his problems in trying to get this research going, expressing considerable frustration because he was trying to produce psychopathology so he could study it rigorously, scientifically, and systematically - and the infant monkeys were clearly not cooperating! According to Harlow's account to me, Bowlby listened patiently to his complaints, and then he said: "Well Harry, unfortunately not every experiment works, not even yours - and by the way, can I go see your lab?" so Harlow had one of his students give Bowlby a tour of the lab.

At that time, and actually unfortunately for many years thereafter in most other primate facilities, the standard way of housing monkeys was to put them in cages by themselves and keep them socially isolated where they could see and hear other monkeys, but not physically interact with them. This was done largely for veterinary purposes. The veterinarians were afraid of disease being spread, and they thought they could prevent that by physically isolating the monkeys from one another-at the time their biggest concern was simply to keep the monkeys alive. Bowlby saw all of these monkeys housed in single cages exhibiting weird stereotypic behaviors, sucking their fingers and toes, and rocking back and forth, which is how rhesus monkeys reared with a lack of physical contact opportunities routinely behave. After his tour Bowlby came back to see Harlow in his office and told him: "Harry, I do not know what your problem is. I just toured your lab and you have more crazy monkeys here than probably exist in any other place on the face of the earth! You do not have to produce psychopathology_you already have it!" Harlow later would say that this just goes to show that one can not have a psychosis unless there is a psychiatrist around to diagnose it. Many years later, when I related that story first time I gave a talk at Cambridge, Robert Hinde came up to me afterward and said: "You have the story right, but you have the wrong person. I am the one who told Harry that." But I have a feeling they both did.

At some point Harlow and Bowlby stopped interacting. I think one of the main reasons was that Harlow retired in 1974, around the time I began corresponding with Bowlby. Maybe Bowlby thought I was the vehicle through which that tradition would keep going - and when Harlow retired, he really retired. He remarried his first wife, moved out of Madison, and went to southern Arizona with her. He had Parkinson's disease at the time, and he later had a stroke and passed away shortly thereafter [in 1981]. The last time I saw him was in late 1980, and I could tell by then that his memory was starting to fade. So it was not that Harlow and Bowlby no longer liked each other but instead that Harlow basically took himself out of the picture.

\section{Harlow's Work and the Influence of Bowlby and Spitz}

I do not think it was Harlow's original intention to refute psychoanalysis. He initially designed his surrogate studies probably more to refute classic drive reduction theory, 
which was absolutely the prominent behaviorist theory at the time, championed by people like Clarke Hull and Herbert Spence. This theory held that primary drives would lead to secondary drives through associations with stimuli that produced the primary drives. So if a mother reduces a child's hunger she becomes a secondary reinforcement object as a result. Harlow hated that theory. His second wife [Margaret] had come out of Spence's lab, and I think that among other things he wanted to show that her mentor was wrong. But Hull was also a major figure in the Department of Psychology at Wisconsin when Harlow first showed up back in 1930. In the years that followed Harlow was discovering all sorts of things that his monkeys could do, such as learning based on curiosity without reinforcement and observational learning that they were not supposed to be able to do according to the basic principles of drive reduction theory. These activities did not require either traditional drive reduction or any other kind of reinforcement- the monkeys would just do these things out of an inherent curiosity.

A second series of insights occurred when Harlow started breeding monkeys [in the early 1950s]. He was especially interested in studying learning phenomena at this time, and one of the things he wanted to do was to understand the development of learning capabilities: how do monkeys learn to learn, how do their cognitive abilities change as they get older? In order to answer those and other questions he needed to test infants, and he wanted infants that were not being cared for by their mothers, because if they were living with their mothers he could not test those infants individually without major disruption. So he separated them from their mothers at birth and developed a neonatal nursery - and he started raising the infants in the nursery. The infants had diapers on the floors of their cages, and Harlow noticed, as had Gertrude van Wagenen (1950) ${ }^{1}$ several years before, that when the infants had their diapers taken away to be cleaned, they got really upset and they kept clinging very strongly to the diapers. ${ }^{2}$ Harlow thought about this for a while and discussed it extensively with his students. At that time, Bill [William A.] Mason was a postdoc in Harlow's lab, and he was very interested in many of these same learning issues himself - he had carried out some of the original studies investigating learning in these infants as they were growing up. Mason, like Harlow, recognised that these infants spent a lot of time clinging to the diapers and he said: "Let's formalise this, let's make something that is more tangible, that they can hang on to, something more permanent." Mason was interested in creating the surrogate as a way of providing that tactile stimulation directly affected the infants. Harlow had the same interest. They had gotten to the point where they had decided to pit surrogates with different types of surfaces against one another: the same wire mesh that was on the floor and sides of the cages versus the cloth in the diapers that the infants seemed to love. The infants spent considerable time hanging onto the cloth, but they did not spend any

\footnotetext{
${ }^{1}$ Van Wagenen (1950, p. 25) noted that the "clinging reaction, undoubtedly initiated by the grasp reflex in the newborn, is unrelated to it physiologically - rather it is an expression of infantile emotional dependence“.

${ }^{2}$ Harlow (1958, p. 675) used "folded gauze diapers to cover the hardware-cloth floors of the cages. The infants clung to these pads and engaged in violent temper tantrums when the pads were removed and replaced for sanitary reasons".
} 
time hanging onto the wire. So they then said: "Let's make a couple of dummies, and we will put one with food but no cloth and one with cloth but no food in each infant's cage and see what happens."

Harlow's recollection of the next step is that while returning from a speaking engagement, he was flying over Detroit when all of a sudden there appeared a surrogate with a face sitting in the seat next to him. He went back to the lab the next morning with the inspiration: "let's put a head with a face on the dummy." So I think that although both Mason and Harlow had the idea using the surrogates to pit food versus tactile contact, it was Harlow who wanted to put a head with a face on the body of the surrogate. Mason did not want to do that - he was very adamant about not putting a head on the surrogate, let alone one with a face, because he did not want to get into the area of affection or anything like that. Instead, he just wanted something that would functionally serve as a vehicle for providing a test of food versus tactile stimulation. Indeed, Mason argued that adding a head with a face would muddy up the situation and make the research sloppy, so when Harlow insisted on adding the head, Mason backed out of the surrogate project. Harlow eventually found a graduate student, Bob [Robert R.] Zimmermann, who agreed to take on the project, and rest is history.

I really think that the insight of adding a head with a face to the surrogate is what suddenly opened up a whole new area of research, allowing Harlow to take something that was initially a test of basic theoretical issues into a whole new research arena that presumably had real relevance for real mothers and real kids. At the time when Harlow met Bowlby for the first time, this was what Bowlby was dealing with in his own mind, and although Harlow did not call it attachment theory per se, it certainly did not hurt to have that kind of empirical foundation showing the strength of the ties that Bowlby was talking about and was starting to develop from his human work. I mean, Harlow was sufficiently creative that he could come up with that insight de novo and immediately recognised what he might be able to do with this research, but I think even he was surprised by how the results of his initial surrogate research took off.

I think it may have been Bowlby who also pointed out to Harlow that those infant monkeys being raised in the nursery were in fact being isolated socially - and in this way may have well provided the impetus to begin formal study of the social and emotional consequences of being reared in social isolation. Harlow's lab was already carrying out studies of the effects of social isolation on the development of cognitive capabilities in monkeys (Mason et al. 1956, was the first of a series of publications on that topic), but the idea to focus on the social and emotional consequences came later, perhaps initially on Hinde's suggestion but almost certainly reinforced by Bowlby. Harlow himself both in public and privately to me said: "It is Bowlby who really got me into this business."

Harlow and his students had actually been studying monkeys reared in functional isolation for some time before that, because it turns out that simply by rearing animals from birth in a nursery and not putting them in with other monkeys, they were doing de facto isolation. What they did subsequently was make the isolation more extreme by putting the infants into tin boxes where they could not even see or hear any other social stimuli, because the previous infants otherwise were growing up in rooms where they could see and hear the other monkeys in the room, even though they could not physically contact them. I am certain that it was Bowlby's influence that taught Harlow to pay attention to things other than the infants' 
learning capabilities, because that is all that they were studying prior to the time that Harlow began interacting with Bowlby.

Bowlby may have pointed out to Harlow: "What you see in these monkeys is what we see in human children raised in institutions," as was reported in studies by Spitz $(1945,1946)$. There followed the first formal studies of the social effects of isolation, in which Harlow and his students deliberately put newborn infant monkeys into these isolation units and then kept them in the units for varying periods of time (03 months, 0-6 months, 6-12 months, 0-12 months); those studies provided the basis for several Ph.D. dissertations. From Guy Rowland's (1964) dissertation, which looked at 6-month-isolates versus 1-year-isolates versus monkeys that were growing up in single cages where they could at least see and hear other monkeys, it became pretty clear that the isolation-reared monkeys were developing grossly abnormal patterns of behavior. When these monkeys were subsequently placed in a playroom with other monkeys of the same age, they were just completely blown away in terms of their total lack of emotional regulation and any sort of normal social repertoires and the appearance of extremely abnormal self-directed behaviors that mother-reared monkeys, and even most single-cage-reared monkeys, simply did not show.

All I can say about the suggestion that Harlow modeled his monkey experiments on the human work done by Spitz is that Harlow once told me: "If you really want to get into this depression business, well start with Spitz and Bowlby." So I do not know for certain if his initial isolation studies were done as a consequence of reading Spitz-indeed, I doubt that was the because in the initial isolation studies, the clear motivation was to study learning in a "pure" environment uncontaminated by other social experiences and things like that. At that time Harlow and his students were convinced that so they were going to study these learning process "right," that is in settings where mothers could not be teaching their kids anything since the infants were being kept by themselves and where it was possible to control their environment to the extent that only the experimenters would be presenting the infants with the stimuli that they would be going to remember or forget. Only later, after Bowlby (and most likely Hinde as well) pointed out to Harlow that these monkeys had some real social and emotional problems, did Harlow begin studying those phenomena systematicallyand when Harlow went after a problem first thing he usually did was get one of his students to do a literature review. Did he know about Spitz's work before then? He certainly knew about those reports by the time he started carrying out those formal studies of the social and emotional consequences of prolonged social isolation.

With respect to the study of the effects of short-term maternal separations, phenomena that in children had clearly been a long-term topic of interest for Bowlby, Harlow was either the first or one of the first to investigate these phenomena systematically in monkeys. I believe Gordon Jensen in Colorado actually beat him to the first publication on this topic by two weeks with a much more limited study (Jensen and Tolman 1962), but Harlow was certainly one of the first to study mother-infant separation in monkeys, that is taking away an infant from its mother for a certain amount of time after an attachment bond has clearly been established and then putting it back with the mother. ${ }^{3}$ Two years later Hinde did essentially the

\footnotetext{
${ }^{3}$ Earlier Hersher et al. (1958) studied separation of goat mothers from their newborns and concluded that separated mothers nursed their own kids less and other kids more than nonseparated mothers.
} 
same thing in a slightly different setting, and indeed maternal separation studies are still being carried out today, but if one goes back to the very first published studies carried out in Harlow's lab (Seay et al. 1962, and Seay and Harlow 1965), in the Introduction and in the Discussion sections of those papers there is nothing but Bowlby. Those monkey studies were modeled exactly on Bowlby's published accounts of the effects of maternal separation on children, including the use of exactly the same terms - "protest," "despair," and "detachment"- that Bowlby had employed in describing the reactions of children following separation from and reunion with their mothers. So the monkey separation paradigms were a direct consequence of the Bowlby and Robertson (Bowlby et al. 1952; Robertson 1953) hospitalization studies, and they are still being employed as experimental manipulations today, 45 years later. The questions of what does separation from an attachment object do to the physiology, to the biochemical systems, to gene expression, in an infant remain relevant today, largely because that manipulation is a powerful enough stimulus to elicit significant changes in those and other biological systems. Bowlby was the first, at least from Harlow's standpoint, to recognize this fact. So absolutely yes, Harlow modeled his monkey separation research on the human clinical reports that Bowlby and his colleagues had put together.

\section{Animal Psychology}

You could say that for the study of attachment-related phenomena it was in a way sheer luck that Harlow was working with rhesus monkeys. In the 1930s he started off like most primatologists at the time: you could either watch monkeys at a zoo or you could have an importer bring them in as pets in order to study them. The primate researchers back then did not know much about how to take care of primates, so most of their monkeys did not survive very long in laboratory settings. Now, if you end up purchasing expensive animals and they die within the first two weeks, they are not going to do you much good. If you look at Harlow's published studies over about the first 10 years of his career, they focus on topics such as object learning in orangutans, gibbons, guenons, langurs, rhesus, and capuchin monkeys, that is, reports of multiple species being tested under different circumstances. If you look more carefully, these other species start dropping out of citations and pretty soon it is only rhesus and capuchin monkeys that are being reported upon. These were the two species that seemed to be able to survive life in those primitive laboratories where they could routinely be maintained for months if not years.

Ultimately, the most interesting part of that history from my standpoint is that in the late 1930s and 1940s Harlow developed a technique for testing the learning capabilities of monkeys using something called the Wisconsin General Test Apparatus (WGTA). This is a device that once you have trained the monkeys to get used to the apparatus, they can be sitting in a cage adjacent to the WGTA, and you as the experimenter have a stimulus tray with two or three shallow wells bored into it hidden from the view of the subject by a movable barrier. On each test trial you put a treat in one of the wells, and you cover it with one type of stimulus and cover the empty well or wells with a different stimulus object or objects, and then 
you raise the barrier and present the monkey with the baited stimulus tray. The subject has to push aside what it thinks is the correct stimulus object and either obtain a reward or not. So this is a very systematic form of testing that one can carry out over hundreds of trials for each subject over multiple sessions, but quite frankly it is boring as hell. Ever since I was a graduate student I have been much more interested in social aspects of primate behavior. When I began training in Harlow's lab, virtually everybody had to do WGTA-testing, but somehow I managed to go all the way through graduate school without ever running a single monkey in a WGTA even once. The testing is clearly boring for the experimenter and takes time up for the monkeys as well. At any rate, Harlow soon discovered that whereas rhesus monkeys would sit still and do this hour after hour, capuchin monkeys, even though they were clever, would not settle down and go through these long-term rigours, and so Harlow eventually concluded: "My choice is between a factory worker and an artist and I am going to choose the factory worker."

Harlow was influenced by the work of the American comparative psychologist Robert Yerkes and his European colleague Wolfgang Köhler. Virtually all the early primatologists knew each other back then and if they did not know each other personally, they were well aware of one another's work. As a graduate student I was shown an old movie that Köhler and Yerkes made of chimps stacking boxes on top of each other to be able to reach a reward. When Harlow first saw that movie [probably back in the 1930s] he said: "If chimps can do it, then why can't capuchins?" So he tried that and eventually made his own movie showing one of his capuchin monkeys stacking boxes and climbing poles to obtain out-of-reach bananas. Harlow absolutely knew about this work involving tool-using by chimps, and he was interested also right from the beginning of his career in studying the complex cognitive capabilities of primates, again because of this notion that monkeys can master complex tasks that rats can not, and can utilize abstract learning processes rather than simple reinforcement chains.

Harlow's interest in characterizing abstract learning processes in monkeys culminated in his discovery of learning sets (Harlow 1949) and that ground-breaking finding probably is what got him elected into the National Academy of Sciences in 1951. This was the finding that if you give monkeys the same discrimination learning task for six trials, initially they get better with each trial and finally by the sixth trial they usually have solved that particular task. After a few hundred different six-trial tasks, they can solve each new task perfectly on the second trial, because if they make the right choice the first time they just stick with that choice and if they make the wrong choice on the first trial, they shift and pick the other stimulus consistently, and therefore they will always solve the problem - and this is viewed as evidence of higher learning, of insightful behavior.

The only sabbatical Harlow ever took was to go to Columbia in 1940, where in one of his lectures the famous German neurologist Kurt Goldstein ${ }^{4}$ stated forcefully that humans are the only ones capable of solving abstract problems. When Harlow returned to Wisconsin he went back to his lab and said: "I will get rhesus monkeys to do this." And he did get the rhesus monkeys to do it. So he later claimed that he was

\footnotetext{
${ }^{4}$ Goldstein had done research on'concrete'and'abstract'learning in brain-damaged soldiers after World War I.
} 
probably the only person who cared about this finding and he was quite sure that Goldstein did not care about anything about monkeys-but Harlow sure did. In a way he was involved in the debate between Wolfgang Köhler and Edward Thorndike regarding insightful versus incremental learning. Once he started working with primates, he said: "I should not waste my time studying the old classic conditioning theories, let's get at this insight business." He had what for most scientists would constitute an entire career studying what we would today call cognitive processes or cognitive development long before he ever began looking at the social, affectional, and emotional capabilities of monkeys - and it was his studies with surrogate mothers that changed all of that.

\section{Harlow's Influence on Bowlby, Ainsworth, and Attachment Theory}

I think at the very least, Harlow provided Bowlby with the empirical backbone for the theoretical foundation of the biological contribution to attachment. He provided evidence that was supportive of a biological basis for attachment, and if that is all he did, that would have been quite enough. I am pretty sure that Harlow's work per se did not really influence Mary Ainsworth's characterization of different attachment styles-I think that her ideas about that were well-developed without any involvement with biology. On the other hand, the notion of a secure base was very clearly supported by Harlow's surrogate findings, especially as depicted in a movie that Harlow made that was eventually shown on national television in the US. I have often said that the finding most people remember from the original surrogate studies was the difference between the cloth-reared and the wire-reared surrogates in terms of the amount of time infants spent in contact with each surrogate type. I think the much more dramatic example of secure-base behavior came when Harlow put these monkeys into a playroom filled with toys and other interesting devices, as depicted in that movie. When an infant was in the playroom with a cloth surrogate present, it typically would initially hang on to the surrogate, clinging to it like crazy, and then after a few seconds the infant would climb off the surrogate, move a short distance away from the surrogate, and then run back to the surrogate for a quick touch, after which it would then leave the surrogate again to explore a little bit more, and then run back to the surrogate, etc.

During some of the test sessions an unfamiliar object would be placed inside the playroom in the presence of the infant - the object that was used in the abovementioned movie was a small toy bear that mechanically played a drum. This particular stimulus initially terrified the infant-it immediately ran back to the surrogate and clung to it for dear life. But after a while, the infant left the surrogate and went over to the toy bear and began to manipulate and then play with it. Indeed, some infants in this situation actually began ripping the toy bear apart after their initial exposure to it. But the manner in which these monkeys initially sought refuge and security by holding on to the cloth surrogate in this novel situation and then used the surrogate as a secure base from which to go out and to explore and even while exploring frequently look back at the surrogate was striking. And the reactions of infants when they were placed in the playroom in the presence of a wire surrogate instead of the cloth surrogate was even more dramatic-most infants would not try 
to contact the wire surrogate or engage in any kind of exploratory behavior. Instead they would typically run to the corner of the playroom and roll up into a ball, screaming all the while, and then remain there for the rest of the test session. I can not imagine that Bowlby would not have been greatly impressed by the infants' vastly different reactions in the playroom depending on the type of surrogate that was present at the time. I am sure that the behavior of those infant monkeys in the playroom solidified his notion of a secure base, of the attachment-like role these surrogates were really providing. So Bowlby may well have had the concept of a secure base before Harlow carried out his surrogate studies, but those studies provided compelling empirical support that was biological in nature, indeed that was coming from another species. It is hard to imagine that Bowlby would not have either felt very satisfied with Harlow's findings or even become inspired to say: "Well, let's put a little more emphasis on this secure-base phenomenon."

\section{Harlow and Bowlby as persons}

It might seem at first glance that Harlow and Bowlby would have very different personalities: Bowlby as a typical upper-middle class Englishman with a stiff upper lip and Harry Harlow as having a much more outgoing personality. Bowlby may have been formal and stiff-upper-lipped in public, but in private he apparently was more engaging. In my interactions with him, which were universally positive and indeed, extremely memorable to me, we would typically start talking about various topics and freely exchange ideas and insights. He often would get terribly excited about some particular point, and any reticence or pretence would quickly disappear under the circumstances. He was also very self-effacing and humble in person. Mario Reda, an Italian cognitive therapist who simply revered Bowlby, once told me that his fondest memory of Bowlby was him saying: "I am just a simple man with simple ideas and I do not have any big notions, I just want to pursue my interests."

Harlow, on the other hand, grew up in a small town in the middle of Iowa, and when he was growing up he was a very shy person, who nevertheless was very smart, quick on his feet, and interested in all sorts of things. He was determined to wear the latest fashion, he was an above-average tennis player (one of his brothers played tennis professionally), and he was an avid and expert bridge player. Harlow was also basically a frustrated English major, which may be one reason why poetry appeared in some of his papers. He grew up with a speech impediment, which initially made public speaking very difficult for him, but when he went to Wisconsin and began teaching introductory psychology to three hundred students at a time three days a week - well, that experience quickly took care of any kind of fear of public speaking, and he even got over his speech impediment. In fact, over the years he became one of the best and most sought-after public speakers of his time. His scientific presentations were just remarkable, indeed often spellbinding. Harlow had a real appreciation of the power of humour, and he knew how to use it. In public, he could be very critical of contemporaries, but if you could get him in a room by himself he would become very humble and self-effacing - and in that way not all that different from Bowlby. I mean, the public appearance is one thing, but if you get either of these guys in a room without anyone else around... 
Harlow could put things rather bluntly and he prided himself on that. He liked to get attention and that was one way to do it - and he loved controversy and did not shy away from it. He expressed ideas in terms other scientists would be afraid to use, would be wary of, or be too careful to want to try. So despite his original shy personality, he often turned to shocking people in his public pronouncements. He discovered that he liked being on stage, and he found out that if you say things that are controversial, you will get asked to be on stage more often-and if you can present your work in ways that focus more on human relationships than its basic theoretical foundations, you get invited to more places.

\section{Influence of Bowlby and Attachment Theory on Suomi's Work}

Bowlby and the attachment theory he developed clearly influenced my own thinking and research right from the very beginning, because I knew about Bowlby's work even before I started working with primates. When I began carrying out separation studies under Harlow's tutelage, Bowlby of course was the inspiration, just as he had been the inspiration for Harlow. The very first time that I met Bowlby at that afore-mentioned symposium in New York, Mary Ainsworth went after me in her public commentary on my presentation, because in my characterization of peerreared monkeys I talked about "attachment between peers," and she argued that peers can never become attached to each other-attachment is only for infants and their mothers. From that day on, whenever I talked to Bowlby he would always emphasize: "Do not listen to Mary-I am very interested in the relationships those peer-reared monkeys have myself. What can they tell us about attachment and in what sense can we consider them more like mother-infant relationships as opposed to the kinds of relationships peers usually develop with each other?" So he inspired-well, I do not know if "inspired" is exactly the right word because Harlow was already talking with me about this - but Bowlby certainly reinforced the view that there were other relations than with the mother that might be important, although they were very likely different. We actually spent almost all of our time together asking each other what we were doing, discussing what was we were each interested in, and what I might do with the monkeys that might be helpful to him in his own research and thinking, and he basically asked on several different occasions: "What have you been doing - and what do you think you would find if you did this to the monkeys or what if you did that that I could incorporate into my own work." Here was this true giant in the field asking a young researcher like me questions like that - it was really something quite special for me personally. But I think a common thread throughout all of our discussions was the basic notion of the importance of social relationships. Social relationships are really the things that make us humans and make rhesus monkeys rhesus monkeys... it is not so much how smart we are or how good we are at finding food, or how well we can avoid predators - it is how we get along with those around us, and what might go wrong in those relationships and why they might be going wrong - and how much of that might be attributable to early attachment experiences. I think the work he was doing with Ainsworth, especially the characterization of different kinds of attachment - and the idea that differences in these early relationships are really meaningful and have long term consequences, was very, very important. 
When I was talking with him about long-term consequences, we were talking only in terms of social capabilities and emotional regulation, because at that time nobody was looking at possible physiological correlates. It was only when William Mason (Wood et al. 1979) and Seymour Levine (Mendoza et al. 1978, 1979; Gunnar et al. 1980) and others started collecting physiological data in attachment and separation studies a few years later that the influence of these relationships and social manipulations on biological functioning became apparent. We now know that those influences affect basically every biological system the body has. But had I not gained an appreciation of the importance of these relationships, I probably would have never looked at these other factors as a consequence of attachment related manipulations.

\section{Conclusion}

The most interesting thing to me about Harlow and Bowlby is that even after all these years, the research areas pioneered by Harlow that clearly influenced Bowlby are still being actively pursued by developmental scientists across multiple disciplines, and the ideas about attachment that Bowlby developed into a formal theory are still in the mainstream of developmental psychology and child psychiatry, and are considered highly relevant in several other fields of clinical study. The contributions of both Harlow and Bowlby have stood the test of time very nicely, and that is the ultimate compliment one can pay to either a scientist or a theoretically oriented clinician, whether they are collecting their own empirical data or are using the findings of others to generate a creative and compelling theory. Attachment theory has basically stood the test of time over the past 50 years, and I believe it will continue to do so well into the future.

Open Access This article is distributed under the terms of the Creative Commons Attribution Noncommercial License which permits any noncommercial use, distribution, and reproduction in any medium, provided the original author(s) and source are credited.

\section{References}

Bowlby, J. (1958). The nature of the child's tie to his mother. International Journal of Psycho-Analysis, 39, 350-373.

Bowlby, J. (1976). Human personality development in an ethological light. In G. Serban, \& A. Kling (Eds.), Animal models in human psychobiology (pp. 27-36). New York: Plenum Press.

Bowlby, J. (1982). Attachment and loss. Vol. 1: Attachment (2nd ed.). New York: Basic Books (Original work published 1969).

Bowlby, J., Robertson, J., \& Rosenbluth, D. (1952). A two-year-old goes to hospital. The Psychoanalytic Study of the Child, 7, 82-94.

Foss, B. M. (1961). Determinants of infant behaviour I. London: Methuen \& Co Ltd.

Foss, B. M. (1963). Determinants of infant behaviour II. London: Methuen \& Co Ltd.

Foss, B. M. (1965). Determinants of infant behaviour III. London: Methuen \& Co Ltd.

Foss, B. M. (1969). Determinants of infant behaviour IV. London: Methuen \& Co Ltd.

Gunnar, M. R., Gonzalez, C. A., \& Levine, S. (1980). The role of peers in modifying behavioral distress and pituitary-adrenal response to a novel environment in year-old rhesus monkeys. Physiology \& Behavior, 25, 795-798.

Harlow, H. F. (1949). The formation of learning sets. Psychological Review, 56, 51-65. 
Harlow, H. F. (1958). The nature of love. American Psychologist, 13, 673-685.

Hersher, L., Moore, A. U., \& Richmond, J. B. (1958). Effect of post partum separation of mother and kid on maternal care in the domestic goat. Science, 128, 1342-1343.

Jensen, G. D., \& Tolman, C. W. (1962). Mother-infant relationship in the monkey, Macaca nemestrina: the effect of brief separation and mother-infant specificity. Journal of Comparative and Physiological Psychology, 55, 131-136.

Mason, W. A., Blazek, N. C., \& Harlow, H. F. (1956). Learning capacities of the infant rhesus monkey. Journal of Comparative and Physiological Psychology, 49, 449-453.

Mendoza, S. P., Coe, C. L., Lowe, E. L., \& Levine, S. (1979). The physiological response to group formation in adult male squirrel monkeys. Psychoneuroendocrinology, 3, 221-229.

Mendoza, S. P., Smotherman, W. P., Miner, M. T., Kaplan, J., \& Levine, S. (1978). Pituitary-adrenal response to separation in mother and infant squirrel monkeys. Developmental Psychobiology, 11, 169-175.

Robertson, J. (1953). Some responses of young children to the loss of maternal care. Nursing Times, April, $382-386$

Rowland, G. L. (1964). The effect of total social isolation upon learning and social behavior in the rhesus monkey. Unpublished doctoral dissertation, University of Wisconsin.

Seay, B., Hansen, E., \& Harlow, H. F. (1962). Mother-infant separation in monkeys. Journal of Child Psychology and Psychiatry, 3, 123-132.

Seay, B., \& Harlow, H. F. (1965). Maternal separation in the rhesus monkey. The Journal of Nervous and Mental Disease, 140, 434-441.

Spitz, R. A. (1945). Hospitalism: an inquiry into the genesis of psychiatric conditions in early childhood. The Psychoanalytic Study of the Child, 1, 53-74.

Spitz, R. A. (1946). Hospitalism: a follow-up report on investigation described in volume I, 1945. The Psychoanalytic Study of the Child, 2, 113-117.

Suomi, S. J. (1976). Factors affecting responses to social separation in rhesus monkeys. In G. Serban, \& A. Kling (Eds.), Animal models in human psychobiology (pp. 27-36). New York: Plenum Press.

Suomi, S. J., Sackett, G. P., \& Harlow, H. F. (1970). Development of sex preference in rhesus monkeys. Developmental Psychology, 3, 326-336.

Van Wagenen, G. (1950). The monkeys. In E. J. Farris (Ed.), The care and breeding of laboratory animals (pp. 1-42). New York: Wiley.

Wood, B. S., Mason, W. A., \& Kenney, M. D. (1979). Contrasts in visual responsiveness and emotional arousal between rhesus monkeys raised with living and those raised with inanimate substitute mothers. Journal of Comparative and Physiological Psychology, 93, 368-377.

Stephen J. Suomi is Head of the Laboratory of Comparative Ethology at the National Institute of Child Health and Human Development (NICHD) in Bethesda, Maryland. He became well-known for his research on the biobehavioral development of rhesus monkeys and other nonhuman primate species. He authored over 300 published articles in refereed scientific journals and chapters in edited volumes. Among his current interest are the interactions between genetic and environmental factors that shape individual developmental trajectories.

Frank C.P. van der Horst is a Ph.D. student and Lecturer at the Centre for Child and Family Studies at Leiden University, The Netherlands. The work presented in this special issue is part of his doctoral thesis on the roots of Bowlby's attachment theory. The defence of this thesis, titled John Bowlby and ethology: a study of cross-fertilization, is scheduled for early 2009.

René van der Veer is Professor of History of Educational Thinking at Leiden University, The Netherlands. His research addresses the work of key educational thinkers such as Gal'perin, Janet, Piaget, Vygotsky, Werner, and Wallon. In a longer study the origin of the idea of the social mind was traced. He is on the Editorial Board of Integrative Psychological and Behavioral Sciences. 